\section{Design of dimensionally stable composites using efficient global optimization method}

\author{
Levent Aydin', Olgun Aydin ${ }^{2}$, H Seçil Artem ${ }^{3}$ and Ali Mert ${ }^{4}$
}

Proc IMechE Part L:

J Materials: Design and Applications

0 (0) $1-13$

(C) IMechE 2016

Reprints and permissions:

sagepub.co.uk/journalsPermissions.nav DOI: |0.1 I77//4644207|666492। pil.sagepub.com

\begin{abstract}
Dimensionally stable material design is an important issue for space structures such as space laser communication systems, telescopes, and satellites. Suitably designed composite materials for this purpose can meet the functional and structural requirements. In this paper, it is aimed to design the dimensionally stable laminated composites by using efficient global optimization method. For this purpose, the composite plate optimization problems have been solved for high stiffness and low coefficients of thermal and moisture expansion. Some of the results based on efficient global optimization solution have been verified by genetic algorithm, simulated annealing, and generalized pattern search solutions from the previous studies. The proposed optimization algorithm is also validated experimentally. After completing the design and optimization process, failure analysis of the optimized composites has been performed based on Tsai-Hill, Tsai-Wu, Hoffman, and Hashin-Rotem criteria.
\end{abstract}

\title{
Keywords
}

Efficient global optimization, laminated composites, dimensional stability, satellite structures, failure criteria

Date received: 17 February 2016; accepted: 28 July 2016

\section{Introduction}

The materials used in aerospace structures like antenna, satellites, and missiles should have such features as low density, high stiffness, and low coefficients of thermal and moisture expansions. Carbon fiber reinforced polymer composite materials can satisfy these requirements with an appropriate stacking sequence. Since moisture and temperature cause some changes on mechanical properties of the polymer matrix composites, dimensional change induced by them is a significant feature in the design of composites. $^{1,2}$ In order to minimize this change, design of dimensionally stable composite materials is required. In the context of composite materials, dimensional stability can be defined as the ability of a material to retain its dimensions when it is subjected to environmental effects such as temperature/moisture changes. ${ }^{3}$ Some researchers have considered design of dimensionally stable composite materials including moisture and/or temperature effects. Bressan et al. ${ }^{4}$ have developed a procedure for the design of structural elements made of carbon-epoxy laminates with low thermal expansion. Le Rich and Gaudin ${ }^{2}$ have studied design of dimensionally stable composite laminates as space materials through stacking sequence optimization considering thermal, hygral and mechanical constraints. Aydin and Artem $^{3}$ have considered multi-objective genetic algorithm (GA) optimization of the carbon fiber laminated composite plates satisfying the conditions low coefficient of thermal expansion (CTE) and high elastic moduli. The study is verified by single objective optimization approach using three different stochastic optimization methods: GA, generalized pattern search, and simulated annealing (SA). Optimal fiber path configurations that minimize the sum of the CTE values along the principal material directions for a class of laminates are presented in the paper by Rangarajan et al. ${ }^{5}$ They have shown and provided a proof that the smallest value of CTEeff is rendered by straight fiber path configurations. It is found that the minimal CTEeff values occur for $[ \pm 45]_{n s}$ lay-ups. "Zero CTE" design problem for hybrid composite materials has been solved by Zhang et al. ${ }^{6}$ This concept is very crucial for the aerospace structures influenced by temperature. Recently, Aydin et al. $^{7}$ have found the optimum stacking sequences of unidirectional flax/polypropylene

\footnotetext{
'Department of Mechanical Engineering, Izmir Katip Çelebi University, Çiğli, İzmir, Turkey

${ }^{2}$ Department of Statistics, Mimar Sinan University, Şişli, İstanbul, Turkey ${ }^{3}$ Department of Mechanical Engineering, Izmir Institute of Technology, Izmir, Turkey

${ }^{4}$ Department of Statistics, Ege University, Bornova, İzmir, Turkey
}

Corresponding author:

Levent AYDIN, Department of Mechanical Engineering, Izmir Katip Çelebi University, Çiğli Ana Yerleşkesi 35620, Çiğli, İzmir, Turkey. Email: leventaydinn@gmail.com 
composite prepregs for minimization of the dimensional changes at varied temperatures by hybrid GA. Optimum flax/polypropylene composite performances have been compared with E-glass/epoxy results. It is shown that flax/polypropylene composites can be used as an alternative to E-glass/epoxy in many types of thermo-mechanical conditions.

Stochastic methods such as GAs, SA, and particle swarm optimization (PSO) have been widely used in different optimization problems of engineering. ${ }^{3,7-10}$ Due to the complexity of design of dimensionally stable composite, it is crucial to use the stochastic optimization methods. Efficient global optimization (EGO) method, used in this study, is one of the stochastic methods and has useful tools for the objective functions for which it is not easy to take their derivatives. One of the pioneer works for EGO is the study of Jones et al. ${ }^{11}$ In their study, authors mentioned about expected improvement (EI) function and fundamentals of EGO process. The EGO process is based on Kriging surrogate models, which were constructed using several sample designs. The EGO process could identify the global optimum with a relatively low evaluation cost. Moreover, the EGO procedure is especially good at modeling the nonlinear,

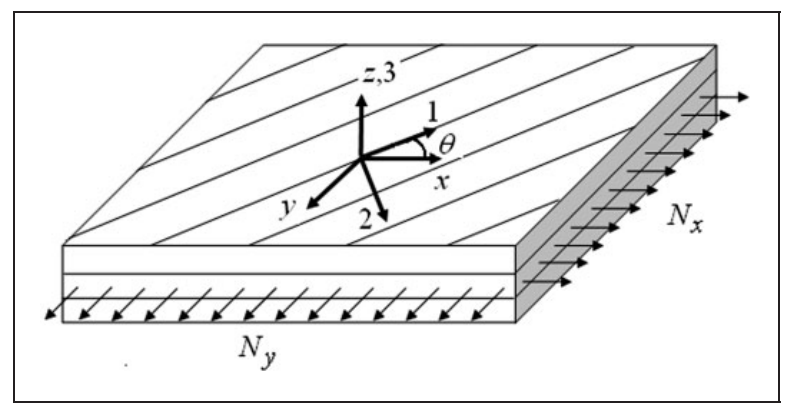

Figure I. A thin fiber reinforced laminated composite subjected to in plane loading. multimodal functions that often occur in many engineering problems such as hat-stiffened composite panel design, ${ }^{12}$ helicopter rotor blades for vibration reduction. $^{13}$

The main objective of the present study is to design dimensionally stable laminated composites satisfying the conditions low CTE and high elastic modulus by combining the EI based search method with kriging approximations (EGO). To achieve this purpose, five different stacking sequence optimization problems including nonlinear constraints have been solved for symmetric balanced 8-layered $\left[ \pm \theta_{1} /\right.$ $\left.\pm \theta_{2}\right]_{S}$, 12-layered $\left[ \pm \theta_{1} / \pm \theta_{2} / \pm \theta_{3}\right]_{S}$, and 16-layered $\left[ \pm \theta_{1} / \pm \theta_{2} / \pm \theta_{3} / \pm \theta_{4}\right]_{S}$ carbon/epoxy laminated composites. MATLAB Symbolic Math Toolbox has been utilized in order to obtain objective functions and constraints. TOMLAB optimization toolbox is used to solve the model problems. In order to show performance of the algorithm, the widely used stochastic search methods GA, SA, generalized pattern search algorithm (GPSA) are applied and comparisons among them are also considered. Moreover, in order to validate the proposed algorithm, an experimental study has been performed. After completing the design process, failure analysis based on Tsai-Hill, Tsai-Wu, Hoffman, and Hashin-Rotem criteria have also been considered in order to give strength performances of the optimally designed laminated composites.

\section{Mechanical analysis}

Classical lamination theory (CLT) can be used to analyze thin laminated composites. Thin laminated composite structure subjected to in plane loadings is shown in Figure 1. In the figure $x, y$, and $z$ define global coordinates of the layered material; and 1, 2, 3 are fiber directions oriented at angle $\theta .{ }^{14,15}$

Representation of laminate convention for the $n$-layered composite material with total thickness $h$ is given in Figure 2.

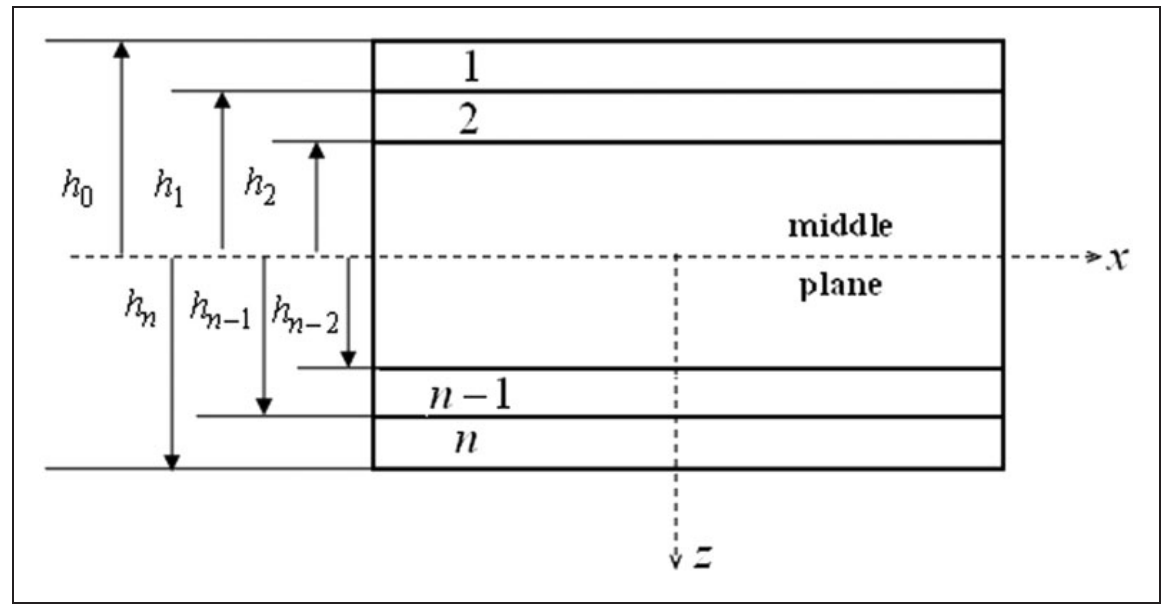

Figure 2. Laminate convention. 
Based on CLT, the total strains including mechanical, thermal, and hygral effects can be expressed as in the following form

$$
\left[\begin{array}{c}
\varepsilon_{x} \\
\varepsilon_{y} \\
\gamma_{x y}
\end{array}\right]=\left[\begin{array}{c}
\varepsilon_{x}^{M} \\
\varepsilon_{y}^{M} \\
\gamma_{x y}^{M}
\end{array}\right]+\left[\begin{array}{c}
\varepsilon_{x}^{T} \\
\varepsilon_{y}^{T} \\
\gamma_{x y}^{T}
\end{array}\right]+\left[\begin{array}{c}
\varepsilon_{x}^{H} \\
\varepsilon_{y}^{H} \\
\gamma_{x y}^{H}
\end{array}\right]
$$

where $[\varepsilon],\left[\varepsilon^{M}\right],\left[\varepsilon^{T}\right],\left[\varepsilon^{H}\right]$ are total, mechanical, thermal and hygral strains, respectively.

Based on CLT, the stress-strain relation for the $k$ th layer of a composite plate has the form:

$$
\begin{aligned}
{\left[\begin{array}{c}
\sigma_{x}^{M} \\
\sigma_{y}^{M} \\
\sigma_{x y}^{M}
\end{array}\right]_{k} } & {\left[\begin{array}{lll}
\bar{Q}_{11} & \bar{Q}_{12} & \bar{Q}_{16} \\
\bar{Q}_{12} & \bar{Q}_{22} & \bar{Q}_{26} \\
\bar{Q}_{16} & \bar{Q}_{26} & \bar{Q}_{66}
\end{array}\right]_{k} } \\
& \times\left(\left[\begin{array}{c}
\varepsilon_{x}^{o} \\
\varepsilon_{y}^{o} \\
\varepsilon_{x y}^{o}
\end{array}\right]+z\left[\begin{array}{c}
\kappa_{x} \\
\kappa_{y} \\
\kappa_{x y}
\end{array}\right]\right. \\
& \left.-\left[\begin{array}{c}
\alpha_{x} \\
\alpha_{y} \\
\alpha_{x y}
\end{array}\right]_{k} \quad \Delta T-\left[\begin{array}{c}
\beta_{x} \\
\beta_{y} \\
\beta_{x y}
\end{array}\right]_{k}\right)
\end{aligned}
$$

where $\left[\bar{Q}_{i j}\right]_{k}$ are the elements of the transformed reduced stiffness matrix, $\left[\varepsilon^{o}\right]$ is the mid-plane strains, $[\kappa]$ is curvatures, $\Delta T, \Delta C$ are temperature and moisture changes, $[\alpha]_{k}$ and $[\beta]_{k}$ are the coefficients of thermal and moisture expansions, respectively.

Applied normal force resultants (force per unit width) $N_{x}^{M}, N_{y}^{M}$ and shear force resultant $N_{x y}^{M}$ on a laminate have the following relations

$$
\begin{aligned}
{\left[\begin{array}{c}
N_{x}^{M} \\
N_{y}^{M} \\
N_{x y}^{M}
\end{array}\right]=} & {\left[\begin{array}{lll}
A_{11} & A_{12} & A_{16} \\
A_{12} & A_{22} & A_{26} \\
A_{16} & A_{26} & A_{66}
\end{array}\right]\left[\begin{array}{c}
\varepsilon_{x}^{o} \\
\varepsilon_{y}^{o} \\
\gamma_{x y}^{o}
\end{array}\right] } \\
& +\left[\begin{array}{lll}
B_{11} & B_{12} & B_{16} \\
B_{12} & B_{22} & B_{26} \\
B_{16} & B_{26} & B_{66}
\end{array}\right]\left[\begin{array}{c}
\kappa_{x} \\
\kappa_{y} \\
\kappa_{x y}
\end{array}\right] \\
& -\left[\begin{array}{c}
N_{x}^{T} \\
N_{y}^{T} \\
N_{x y}^{T}
\end{array}\right]-\left[\begin{array}{c}
N_{x}^{C} \\
N_{y}^{C} \\
N_{x y}^{C}
\end{array}\right]
\end{aligned}
$$

The matrices $[A]$ and $[B]$ appearing in equation (3) are defined as

$$
\begin{aligned}
& A_{i j}=\sum_{k=1}^{n}\left(\bar{Q}_{i j}\right)_{k}\left(h_{k}-h_{k-1}\right) \\
& B_{i j}=\frac{1}{2} \sum_{k=1}^{n}\left(\bar{Q}_{i j}\right)_{k}\left(h_{k}^{2}-h_{k-1}^{2}\right) \quad(i, j=1,2,6)
\end{aligned}
$$

and $\left[N^{T}\right],\left[N^{C}\right]$ are the resultant thermal and hygral forces, respectively:

$$
\begin{aligned}
& {\left[\begin{array}{c}
N_{x}^{T} \\
N_{y}^{T} \\
N_{x y}^{T}
\end{array}\right]=\Delta T \sum_{k=1}^{n}\left[\begin{array}{lll}
\bar{Q}_{11} & \bar{Q}_{12} & \bar{Q}_{16} \\
\bar{Q}_{12} & \bar{Q}_{22} & \bar{Q}_{26} \\
\bar{Q}_{16} & \bar{Q}_{26} & \bar{Q}_{66}
\end{array}\right]_{k}} \\
& \times\left[\begin{array}{c}
\alpha_{x} \\
\alpha_{y} \\
\alpha_{x y}
\end{array}\right]_{k}\left(h_{k}-h_{k-1}\right) \\
& {\left[\begin{array}{c}
N_{x}^{C} \\
N_{y}^{C} \\
N_{x y}^{C}
\end{array}\right]=\Delta C \sum_{k=1}^{n}\left[\begin{array}{lll}
\bar{Q}_{11} & \bar{Q}_{12} & \bar{Q}_{16} \\
\bar{Q}_{12} & \bar{Q}_{22} & \bar{Q}_{26} \\
\bar{Q}_{16} & \bar{Q}_{26} & \bar{Q}_{66}
\end{array}\right]_{k}} \\
& \times\left[\begin{array}{c}
\beta_{x} \\
\beta_{y} \\
\beta_{x y}
\end{array}\right]_{k}\left(h_{k}-h_{k-1}\right)
\end{aligned}
$$

In order to avoid complicated calculation for CTE, coefficient of moisture expansion (CME) and elastic moduli of the composite, it is also convenient to introduce the effective elastic properties of symmetric balanced or symmetric cross-ply laminated plates subjected to in-plane loading. The effective thermal and moisture expansion coefficients and elastic moduli can be calculated using the following relations ${ }^{15}$

$$
\left[\begin{array}{c}
\alpha_{x} \\
\alpha_{y} \\
\alpha_{x y}
\end{array}\right]=\left[\begin{array}{c}
\varepsilon_{x}^{0} \\
\varepsilon_{y}^{0} \\
\gamma_{x y}^{0}
\end{array}\right]_{\substack{\Delta T=0 \\
\Delta T=1}}=\left[\begin{array}{lll}
A_{11}^{*} & A_{12}^{*} & A_{16}^{*} \\
A_{12}^{*} & A_{22}^{*} & A_{26}^{*} \\
A_{16}^{*} & A_{26}^{*} & A_{66}^{*}
\end{array}\right]\left[\begin{array}{c}
N_{x}^{T} \\
N_{y}^{T} \\
N_{x y}^{T}
\end{array}\right]
$$

$$
\begin{aligned}
& {\left[\begin{array}{c}
\beta_{x} \\
\beta_{y} \\
\beta_{x y}
\end{array}\right]=\left[\begin{array}{c}
\varepsilon_{x}^{0} \\
\varepsilon_{y}^{0} \\
\gamma_{x y}^{0}
\end{array}\right]_{\substack{\Delta C=1 \\
\Delta T=0}}=\left[\begin{array}{lll}
A_{11}^{*} & A_{12}^{*} & A_{16}^{*} \\
A_{12}^{*} & A_{22}^{*} & A_{26}^{*} \\
A_{16}^{*} & A_{26}^{*} & A_{66}^{*}
\end{array}\right]\left[\begin{array}{c}
N_{x}^{C} \\
N_{y}^{C} \\
N_{x y}^{C}
\end{array}\right]} \\
& E_{x}=\frac{1}{h A_{11}^{*}} \\
& E_{y}=\frac{1}{h A_{22}^{*}}
\end{aligned}
$$

where $\left[A^{*}\right]=[A]^{-1}$

The material properties used in calculation of elements of the stiffness matrices and the effective properties are given in Table 1.

\section{Failure analysis}

Many studies about optimum design of composite materials consider failure criteria based on (i) noninteractive theories (e.g., maximum stress or maximum strain), (ii) interactive theories (e.g., Tsai-Hill, 
Table I. Carbon/epoxy (P75/934) composite material properties. ${ }^{14}$

\begin{tabular}{lll}
\hline Property & Value & Description \\
\hline$E_{11}(\mathrm{GPa})$ & 277.3 & Elastic modulus in longitudinal direction \\
$E_{22}(\mathrm{GPa})$ & 7.1 & Elastic modulus in transverse direction \\
$v_{12}$ & 0.29 & Poisson's Ratio \\
$G_{12}(\mathrm{GPa})$ & 3.49 & Shear modulus \\
$\alpha_{11}\left(10^{-6} /{ }^{\circ} \mathrm{C}\right)$ & -1.00 & Coefficient of thermal expansion in longitudinal direction \\
$\alpha_{22}\left(10^{-6} /{ }^{\circ} \mathrm{C}\right)$ & 22.42 & Coefficient of thermal expansion in transverse direction \\
$\beta_{11}\left(10^{-6} / \% \mathrm{M}\right)$ & 15.65 & Coefficient of moisture expansion in longitudinal direction \\
$\beta_{22}\left(10^{-6} / \% \mathrm{M}\right)$ & 669.9 & Coefficient of moisture expansion in transverse direction \\
$\sigma_{1}^{T}(\mathrm{MPa})$ & 1500 & Tensile strength in longitudinal direction \\
$\sigma_{1}^{C}(\mathrm{MPa})$ & 1250 & Compressive strength in longitudinal direction \\
$\sigma_{2}^{T}(\mathrm{MPa})$ & 50 & Tensile strength in transverse direction \\
$\sigma_{2}^{C}(\mathrm{MPa})$ & 200 & Compressive strength in transverse direction \\
$\sigma_{12}^{F}(\mathrm{MPa})$ & 100 & In-plane shear strength \\
\hline
\end{tabular}

Tsai-Wu or Hoffman), and (iii) partially interactive or failure mode-based theories (e.g., Puck or HashinRotem failure criterion). ${ }^{16}$ In the following section, Tsai-Hill, Tsai-Wu, Hoffman, and Hashin-Rotem criteria used in this study are introduced.

\section{Tsai-Hill criterion}

Tsai-Hill failure criterion for the strengths of the lamina can be represented in the following form ${ }^{17}$

$$
\frac{\sigma_{1}^{2}}{\left(\sigma_{1}^{F}\right)^{2}}-\frac{\sigma_{1} \sigma_{2}}{\left(\sigma_{1}^{F}\right)^{2}}+\frac{\sigma_{2}^{2}}{\left(\sigma_{2}^{F}\right)^{2}}+\frac{\tau_{12}^{2}}{\left(\tau_{12}^{F}\right)^{2}}<1
$$

where

$\sigma_{1}, \sigma_{2} \quad$ maximum normal stresses,

$\tau_{12}$ maximum shear stress in the lamina,

$\sigma_{1}^{F}, \sigma_{2}^{F} \quad$ strength in longitudinal and transverse

$\tau_{12}^{F} \quad \begin{aligned} & \text { directions, } \\ & \text { shear strength in 1-2 plane, }\end{aligned}$

\section{Tsai-Wu criterion}

Tsai-Wu failure theory is a phenomenological failure theory based on total strain energy. According to the theory, failure does not occur in the lamina if the following condition is satisfied ${ }^{18}$

$$
F_{11} \sigma_{1}^{2}+F_{22} \sigma_{2}^{2}+F_{66} \tau_{12}^{2}+F_{1} \sigma_{1}+F_{2} \sigma_{2}+2 F_{12} \sigma_{1} \sigma_{2}<1
$$

where

$$
\begin{aligned}
& F_{11}=\frac{1}{\sigma_{1}^{T} \sigma_{1}^{C}}, \quad F_{22}=\frac{1}{\sigma_{2}^{T} \sigma_{2}^{C}}, \quad F_{1}=\frac{1}{\sigma_{1}^{T}}-\frac{1}{\sigma_{1}^{C}} \\
& F_{2}=\frac{1}{\sigma_{2}^{T}}-\frac{1}{\sigma_{2}^{C}}, \quad F_{66}=\frac{1}{\left(\tau_{12}^{F}\right)^{2}}, \quad F_{12}=-\frac{1}{2} \sqrt{F_{11} F_{22}}
\end{aligned}
$$

$\sigma_{1}^{T}, \sigma_{1}^{C} \quad$ tensile and compressive strength in longitudinal direction,

$\sigma_{2}^{T}, \sigma_{2}^{C} \quad$ tensile and compressive strength in transverse direction,

There are two significant advantages of this theory: (i) there is interaction between the stress components and (ii) the theory does distinguish between the tensile and compressive strengths. Main disadvantage of this theory is the determination of strength component $F_{12} \cdot{ }^{19}$

\section{Hoffman criterion}

The Hoffman failure theory ${ }^{20}$ use a second-order polynomial in stress to describe a failure surface in the lamina. This theory implies that failure does not occur if the following condition is satisfied

$$
F_{11} \sigma_{1}^{2}+F_{22} \sigma_{2}^{2}+F_{66} \tau_{12}^{2}+F_{1} \sigma_{1}+F_{2} \sigma_{2}+2 F_{12} \sigma_{1} \sigma_{2}<1
$$

where

$$
\begin{aligned}
& F_{11}=\frac{1}{\sigma_{1}^{T} \sigma_{1}^{C}}, \quad F_{22}=\frac{1}{\sigma_{2}^{T} \sigma_{2}^{C}}, \quad F_{1}=\frac{1}{\sigma_{1}^{T}}-\frac{1}{\sigma_{1}^{C}} \\
& F_{2}=\frac{1}{\sigma_{2}^{T}}-\frac{1}{\sigma_{2}^{C}}, \quad F_{66}=\frac{1}{\left(\tau_{12}^{F}\right)^{2}}, \quad F_{12}=-\frac{1}{2}\left(F_{11}+F_{22}\right)
\end{aligned}
$$

\section{Hashin-Rotem criterion}

Hashin-Rotem failure theory ${ }^{21}$ is a partially interactive criteria and includes two failure mechanisms: fiber failure and matrix failure, distinguishing between tension and compression.

$$
\sigma_{1}=\sigma_{1}^{T} \text { Fiber failure in tension: }\left(\sigma_{1}>0\right)
$$


Table 2. Model problems for carbon/epoxy laminated composite designs.

\begin{tabular}{|c|c|c|c|}
\hline Problems & Objective & Constraints & Loading \\
\hline I & $\begin{array}{l}\text { Maximization of } \boldsymbol{E}_{\mathbf{x}} \\
\text { for }\left[ \pm \theta_{1} / \pm \theta_{2}\right]_{S}\end{array}$ & $\alpha_{x} \leqslant-2.63 .10^{-6} /{ }^{\circ} \mathrm{C}$ & $\begin{array}{l}F_{x}=20 \mathrm{kN}, F_{y}=20 \mathrm{kN}, F_{x y}=0 \\
\Delta \boldsymbol{T}=-150^{\circ} \mathrm{C}, \Delta C=0 \%\end{array}$ \\
\hline 2 & $\begin{array}{l}\text { Maximization of } \boldsymbol{E}_{\mathbf{x}} \\
\text { for }\left[ \pm \theta_{1} / \pm \theta_{2}\right]_{S}\end{array}$ & $\begin{array}{l}\alpha_{X} \leqslant-2.31 \cdot 10^{-6} /{ }^{\circ} \mathrm{C} \\
E_{Y} \geqslant 9.67 \mathrm{GPa}\end{array}$ & $\begin{array}{l}r_{x}=20 \mathrm{KIN}, r_{y}=20 \mathrm{KIN}, r_{x y}=0 \\
\Delta \boldsymbol{T}=-150^{\circ} \mathrm{C}, \Delta \boldsymbol{C}=0 \%\end{array}$ \\
\hline 3 & $\begin{array}{l}\text { Maximization of } \boldsymbol{E}_{\mathbf{x}} \\
\text { for }\left[ \pm \theta_{1} / \pm \theta_{2}\right]_{S}\end{array}$ & $\alpha_{x} \leqslant-3.21 .10^{-6} /{ }^{\circ} \mathrm{C}$ & $\begin{array}{l}F_{x}=50 \mathrm{kN}, F_{y}=\mathrm{I} \mathrm{kN}, F_{x y}=0 \\
\Delta \boldsymbol{T}=-150^{\circ} \mathrm{C}, \Delta C=2 \%\end{array}$ \\
\hline 4 & $\begin{array}{l}\text { Maximization of } \boldsymbol{E}_{\mathbf{x}} \\
\text { for }\left[ \pm \theta_{1} / \pm \theta_{2} / \pm \theta_{3}\right]_{S}\end{array}$ & $\begin{array}{l}\alpha_{X}<-2.5 .10^{-6} /{ }^{\circ} \mathrm{C} \\
E_{Y} \geqslant 8.4 \mathrm{GPa}\end{array}$ & $\begin{array}{l}F_{x}=50 \mathrm{kN}, F_{y}=\mathrm{I} \mathrm{kN}, F_{x y}=0 \\
\Delta \boldsymbol{T}=-150^{\circ} \mathrm{C}, \Delta \boldsymbol{C}=2 \%\end{array}$ \\
\hline 5 & $\begin{array}{l}\text { Minimization of } \boldsymbol{\alpha}_{\boldsymbol{x}} \\
\text { for }\left[ \pm \theta_{1} / \pm \theta_{2} / \pm \theta_{3} \pm \theta_{4}\right]_{S}\end{array}$ & $E_{x} \geqslant 18.4 \mathrm{GPa}$ & - \\
\hline
\end{tabular}

$-\sigma_{1}=\sigma_{1}^{C} \quad$ Fiber failure in compression: $\left(\sigma_{1}<0\right)$

$\left(\frac{\sigma_{2}}{\sigma_{2}^{T}}\right)^{2}+\left(\frac{\tau_{12}}{\tau_{12}^{F}}\right)^{2}=1 \quad$ Matrix failure in tension: $\left(\sigma_{2}>0\right)$

$$
\left(\frac{\sigma_{2}}{\sigma_{2}^{C}}\right)^{2}+\left(\frac{\tau_{12}}{\tau_{12}^{F}}\right)^{2}=1
$$

Matrix failure in compression: $\left(\sigma_{2}<0\right)$

\section{Optimization}

Optimization techniques can be classified as traditional and non-traditional. Traditional optimization techniques, such as constrained variation and Lagrange multipliers, are analytical and find the optimum solution of only continuous and differentiable functions. Since composite design problems generally are very complex and have discrete search spaces, the traditional optimization techniques cannot be used in this area. In these cases, the use of stochastic optimization methods such as GA, PSO, EGO algorithms, etc. is appropriate. In composite laminate design problems, derivative calculations or their approximations are impossible to obtain and often costly. Therefore, stochastic search methods have also the advantage of requiring no gradient information of the objective functions and the constraints.

The optimization problems including fiber orientation angles $\theta_{1}, \theta_{2}, \ldots, \theta_{n}$ as design variables can be stated as follows

$$
\begin{aligned}
& \operatorname{minimize} \quad f\left(\theta_{1}, \theta_{2}, \ldots, \theta_{n}\right) \\
& \text { such that } g_{i}\left(\theta_{1}, \theta_{2}, \ldots, \theta_{n}\right) \geqslant 0 \quad i=1,2, \ldots, r \\
& p_{j}\left(\theta_{1}, \theta_{2}, \ldots, \theta_{n}\right)=0 \quad j=1,2, \ldots, m
\end{aligned}
$$

where $f$ is objective function, and $g, p$ are the constraints of the problem. In composite design and optimization problems, mass, stiffness, displacements, residual stresses, thickness, vibration frequencies, buckling loads, cost, etc. are also used as objective functions. ${ }^{22}$ In this study, CTEs and elastic moduli are considered as objective functions of the optimization problems (model problems 1-5, see Table 2) by using EGO method.

\section{EGO}

EGO is closely related with Kriging metamodeling technique. The method often requires the fewest function evaluations, provides a credible stopping rule based on EI, and uses Kriging metamodel to find new sampling points. In this optimization method, first, initial data set is created with the aid of an experimental design approach. After that, a metamodel is constructed using Kriging technique for the data set. Based on the Kriging metamodel, EI function is created. The function is maximized to obtain an infill sampling point. Finally, the point is added to the initial data set and this procedure is continued iteratively until there is no significant change in the EI function value. The procedure for EGO is also summarized schematically in Figure 3.

While giving detailed information concerning the procedure, it is suitable to start with mentioning Kriging metamodeling technique that can be mathematically expressed as ${ }^{11}$

$$
y\left(\mathbf{x}^{(i)}\right)=\mu+\epsilon\left(\mathbf{x}^{(i)}\right), \quad(i=1, \ldots, n)
$$

In this equation, $y\left(\mathbf{x}^{(i)}\right)$ is the associated response value, $\mu$ is the mean of the stochastic process, $\epsilon\left(\mathbf{x}^{(i)}\right)$ normally distributed, independent error terms with mean zero and variance $\sigma^{2}$ and $\mathbf{x}^{(i)}=\left(x_{1}^{(i)}, \ldots, x_{k}^{(i)}\right)$. This model is a stochastic process model because the error term $\epsilon(\mathbf{x})$ is a stochastic process, it is a set of correlated random variables indexed by the $k$-dimensional space of $x$. Correlation between $\epsilon\left(\mathbf{x}^{(i)}\right)$ and $\epsilon\left(\mathbf{x}^{(j)}\right)$ is defined as

$$
\begin{aligned}
\operatorname{Corr}\left[\epsilon\left(\mathbf{x}^{i}\right), \epsilon\left(\mathbf{x}^{j}\right)\right] & =\sum_{h=1}^{k} \theta_{h}\left|x_{h}^{i}-x_{h}^{j}\right|^{p_{h}}, \quad \theta_{h} \geqslant 0, \\
p_{h} \in[1,2], \quad i, j & =(1, \ldots, n)
\end{aligned}
$$




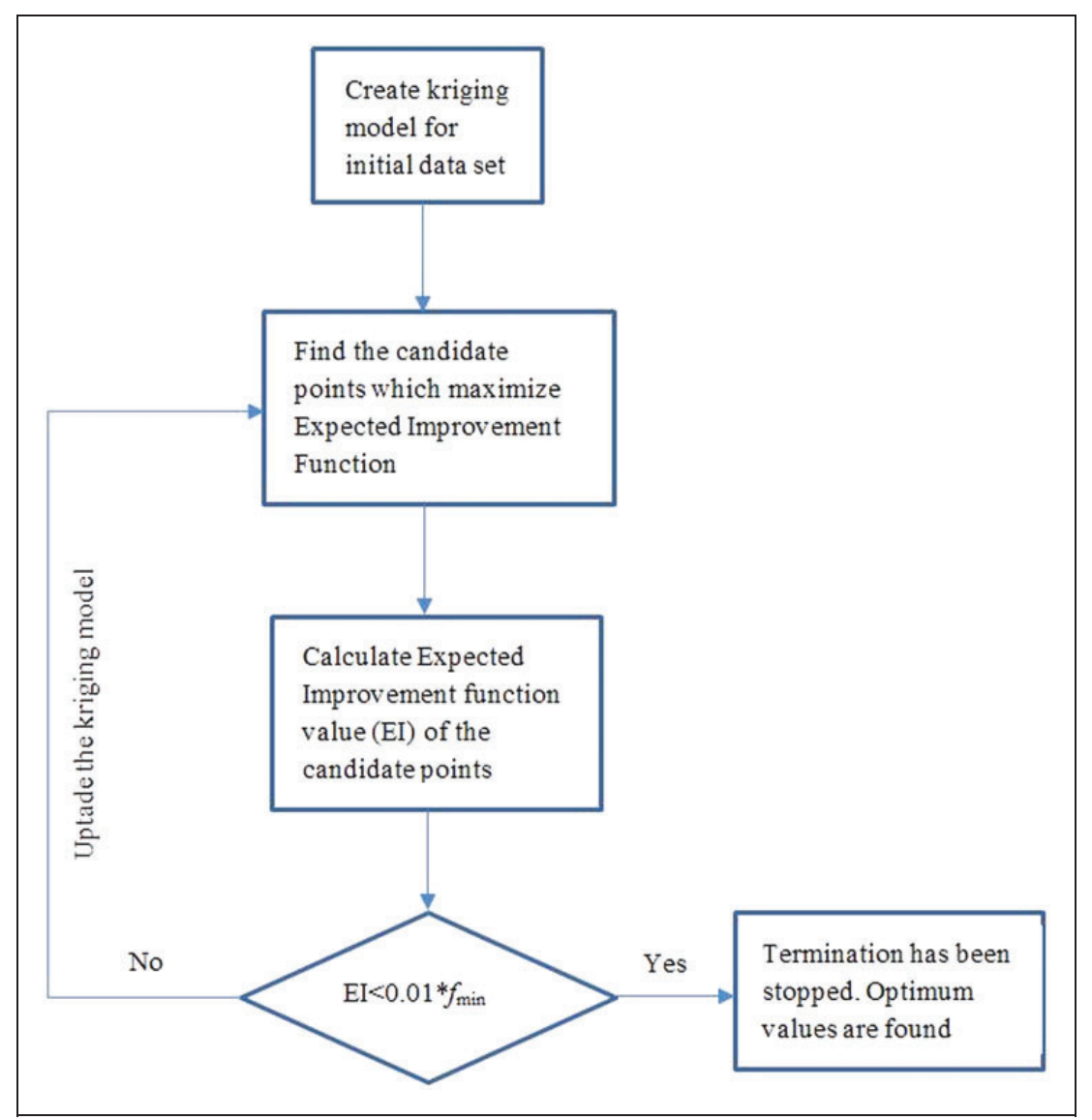

Figure 3. Flowchart of efficient global optimization method.

where $\theta_{h}$ denotes measurement of the importance of the variable $x_{h}, p_{h}$ is smoothness parameter of the function in coordinate direction $h .^{8}$ The parameters $\mu$ and $\sigma^{2}$ are unknowns and they could be estimated with a combination of the parameters of correlation $\theta_{h}$ and $p_{h}$. In order to estimate the parameters, maximum likelihood estimation technique can be used. As a consequence, likelihood function can be written as ${ }^{11}$

$$
L=\frac{1}{(2 \pi)^{\frac{\mathrm{n}}{2}}\left(\sigma^{2}\right)^{\frac{\mathrm{n}}{2}}|\mathbf{R}|^{\frac{1}{2}}} \exp \left[-\frac{(\mathbf{y}-1 \mu)^{\prime} \mathbf{R}^{-1}(\mathbf{y}-1 \mu)}{2 \sigma^{2}}\right]
$$

where $\mathbf{y}=\left(y^{(i)}, \ldots, y^{(n)}\right)$ denote the $n$-vector of observed response values and $\mathbf{1}$ is a $n$-vector of ones. Because $\mu$ and $\sigma^{2}$ are unknowns, estimated values of $\mu$ and $\sigma^{2}$ can be used and the estimated values are written by following equations, respectively.

$$
\begin{aligned}
\hat{\mu} & =\frac{1^{\prime} \mathbf{R}^{-1} \mathbf{y}}{1^{\prime} \mathbf{R}^{-1} 1} \\
\hat{\sigma}^{2} & =\frac{(\mathbf{y}-1 \hat{\mu})^{\prime} \mathbf{R}^{-1}(\mathbf{y}-1 \hat{\mu})}{n}
\end{aligned}
$$

After these definitions, likelihood function is converted to "concentrated likelihood function" which depends only $\theta_{h}$ and $p_{h}$. In this step, we need to find optimum $\theta_{h}$ and $p_{h}$ which maximize the "concentrated likelihood function."

Now, the estimated value of response at $\mathrm{x}^{*}$, not observed previously, can be defined as in the following form

$$
\hat{y}\left(\mathbf{x}^{*}\right)=\hat{\mu}+\mathbf{r}^{\prime} \mathbf{R}^{-1}(\mathbf{y}-1 \hat{\mu})
$$

In the equation, $\hat{y}\left(\mathbf{x}^{*}\right)$ is the best linear unbiased predictor of $y\left(\mathbf{x}^{*}\right), \mathbf{r}$ determines the correlations between the error terms at $\mathbf{x}^{*}$ and the error terms at the previously observed points $\mathbf{x}$ and can be defined as

$$
\mathbf{r}\left(\mathbf{x}^{*}\right) \equiv \operatorname{Corr}\left[\epsilon\left(\mathbf{x}^{*}\right), \epsilon(\mathbf{x})\right]
$$

Detailed information about derivation of the expression given in equation (24) can also be found in the study of Sacks et al. ${ }^{23}$ After creating the model given by equation (24), some validation techniques must be applied. For this purpose, well known cross-validation method is used. In this method, a prediction is generated with one data point excluded from the data set and then checked if that data point falls within a certain confidence interval for the prediction. If the test fails, appropriate transformations such as log or inverse may be applied to the response values. ${ }^{11}$ 
Table 3. Comparisons of optimization results for EGO against SA, GA, and GPSA.

\begin{tabular}{|c|c|c|c|c|c|c|}
\hline Solutions & $\begin{array}{l}\text { Optimization } \\
\text { method }\end{array}$ & $\begin{array}{l}E_{x} \\
(\mathrm{GPa})\end{array}$ & $\begin{array}{l}E_{y} \\
(\mathrm{GPa})\end{array}$ & $\begin{array}{l}\alpha_{x} \\
\left(10^{-6} /{ }^{\circ} \mathrm{C}\right)\end{array}$ & $\begin{array}{l}\beta_{x} \\
\left(10^{-6} / \% M\right)\end{array}$ & $\begin{array}{l}\text { Stacking } \\
\text { sequence }\end{array}$ \\
\hline Ia & EGO & 189.49 & 7.1 & -2.63 & -29.91 & $( \pm 16.1)_{2 s}$ \\
\hline Ib & $S A^{3}$ & 188.26 & 7.1 & -2.65 & -30.43 & $( \pm 17 / \mp 15.3)_{s}$ \\
\hline Ic & GPSA $^{3}$ & I 89.54 & 7.1 & -2.63 & -29.99 & $( \pm 16 / \pm 16.1)_{s}$ \\
\hline Id & $G A^{3}$ & 188.93 & 7.1 & -2.64 & -30.25 & $( \pm 16.1)_{2 s}$ \\
\hline $2 a$ & EGO & 183.38 & 9.7 & -2.31 & -21.16 & $(\mp 5.8 / \pm 25.6)_{s}$ \\
\hline $2 b$ & $S A^{3}$ & 182.00 & 9.8 & -2.32 & -21.38 & $( \pm 6 / \pm 25.8)_{s}$ \\
\hline $2 c$ & GPSA $^{3}$ & 183.48 & 9.7 & -2.31 & -21.20 & $( \pm 25.6 / \pm 5.8)_{s}$ \\
\hline $2 d$ & $\mathrm{GA}^{3}$ & 183.48 & 9.7 & -2.31 & -21.10 & $(\mp 5.8 / \pm 25.6)_{s}$ \\
\hline $3 a$ & EGO & 152.65 & 7.1 & -3.22 & -46.41 & $( \pm 19)_{2 s}$ \\
\hline $3 \mathbf{b}$ & $S A^{3}$ & 151.01 & 7.2 & -3.23 & -46.66 & $( \pm 17.8 / \pm 20.5)_{s}$ \\
\hline $3 c$ & GPSA $^{3}$ & 152.65 & 7.1 & -3.22 & -46.41 & $( \pm 18.9 / \pm 19.1)_{s}$ \\
\hline 3d & $\mathrm{GA}^{3}$ & 152.66 & 7.1 & -3.22 & -46.38 & $(\mp|9.3 / \mp| 8.7)_{s}$ \\
\hline 4 & EGO & I83.04 & 8.39 & -2.50 & -26.38 & $( \pm 24.6 / \pm 8.4 / \pm 16.1)_{s}$ \\
\hline 5 & EGO & 40.36 & 8.07 & -5.24 & -102.84 & $( \pm 32.1)_{45}$ \\
\hline
\end{tabular}

Note: Bolded values represent the optimized objective function values.

Following the completion of the investigative process given above EI criteria can be introduced as:

Denoting the function $y=f(x)$, the improvement I over $f_{\min }$ can be defined as the minimum response value of $f(x)$ after $n$ evaluations and expressed as ${ }^{24}$

$$
I=\left\{\begin{array}{cc}
\left(f_{\min }-y\right), & y<f_{\min } \\
0, & \text { otherwise }
\end{array}\right.
$$

In order to obtain the EI, expected value of $I(\mathrm{E}(\mathrm{I}))$ need to be calculated considering that $y$ has a normal distribution with $\hat{y}$ mean and $s^{2}$ variance. $E(I)$ is now calculated by the following integration

$$
E(I)=\int_{-\infty}^{f_{\min }}\left(f_{\min }-y\right) \phi(y) d y
$$

and EI function can be written as

$$
E I=\left(f_{\text {min }}-\hat{y}\right) \Phi\left(\frac{f_{\text {min }}-\hat{y}}{s}\right)+s \phi\left(\frac{f_{\text {min }}-\hat{y}}{s}\right)
$$

where $\Phi($ ) is cumulative distribution function (CDF) and $\phi()$ is probability density function (PDF) of a standard Gaussian variable.

\section{Problem definition}

In this study, stacking sequences optimization problems, presented in Table 2, have been solved by using EGO method for 8-layered $\left[ \pm \theta_{1} / \pm \theta_{2}\right]_{S}$, 12-layered $\left[ \pm \theta_{1} / \pm \theta_{2} / \pm \theta_{3}\right]_{S}, \quad$ and 16-layered $\left[ \pm \theta_{1} / \pm \theta_{2} /\right.$ $\left.\pm \theta_{3} / \pm \theta_{4}\right]_{S}$ carbon/epoxy laminated composites having low CTE and high elastic moduli. The laminate lay-up is limited to a symmetric and balanced so as to avoid extension-bending coupling effects. Moreover, to prevent excessive interlaminar stress in the laminated composites, ply contiguous constraint is taken into consideration. The fiber orientation angles $\theta_{1}, \theta_{2}, \theta_{3}, \theta_{4}$ are selected as design variables and the limiting values are $-90 \leqslant \theta_{1}, \theta_{2}, \theta_{3}, \theta_{4} \leqslant 90$ in the continuous domain. The fiber volume fraction and thickness of each layer are assumed as 0.50 and $150 \cdot 10^{-6} \mathrm{~m}$, respectively.

Since the hygrothermal effects are entirely analogous mathematically to the thermal effect, resulting fiber orientation angels automatically minimize the CME and this gives an important advantage for the materials especially used in satellite structures. Therefore, it is sufficient to minimize the CTE only and not necessary to solve a new optimization problem in order to minimize the CME of the laminated composites. $^{25}$

Model problems 1-5 defined in Table 2 are nonlinear single objective optimization problems with nonlinear constraints. In all the problems, CLT is utilized to determine the objective functions (the effective elastic moduli and the effective CTEs) of optimization problems. By using EGO method, the optimum fiber orientation angles of each layer have been determined. After obtaining optimum solutions of the model problems, the corresponding material properties have also been calculated and presented in Table 3 .

\section{Results and discussion}

In this section, results of optimization studies are presented. In order to validate the present algorithm EGO, solutions of the model problems 1-3 have been compared to that of the corresponding GA, SA, and GPSA results from the literature and the results are presented in Table 3. After these validations have been done, two independent designoptimization problems (model problems 4 and 5) 


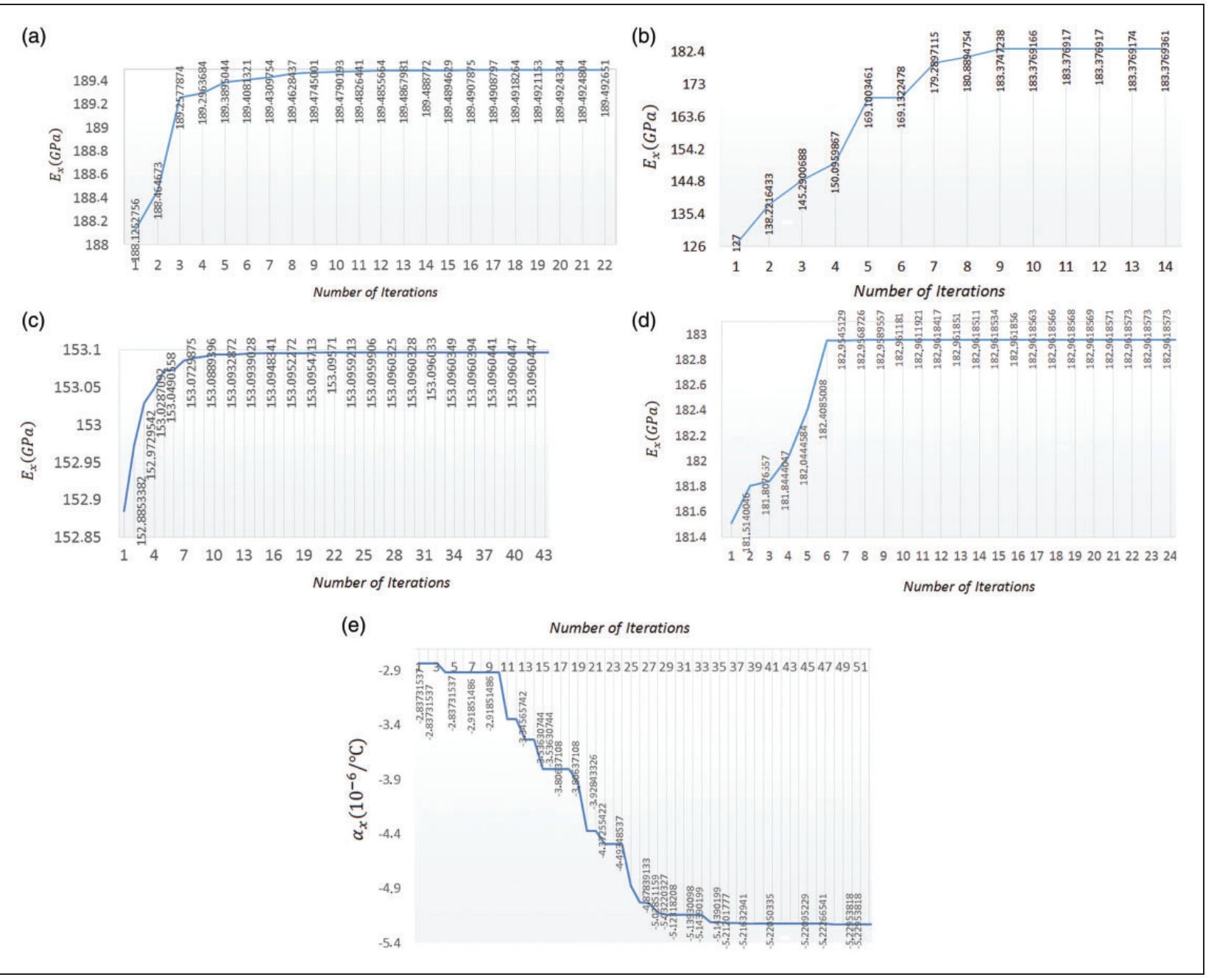

Figure 4. Convergence curves for design of the model problems.

have been solved by using EGO. The results showing evolution of the objective functions for all designs during the optimization process with EGO are also presented in Figure 4(a) to (e).

As seen from Table 3, in model problem 1, (i) EGO solution for elastic modulus is better than SA and GA solutions, (ii) the same stacking sequences $( \pm 16.1)_{2 s}$ have been obtained based on EGO and GA. For model problem 2, (i) all the methods produce very close values, (ii) as in model problem 1, the same stacking sequences $(\mp 5.8 / \pm 25.6)_{s}$ that maximize the elastic modulus of the laminated composite are found based on EGO and GA. Model problem 3 considers combination of mechanical, thermal, and hygral effects. Although the stacking sequences estimations of the algorithms are different, the same results are obtained by EGO and GPSA $\left(E_{x}=152.65 \mathrm{GPa}\right)$. Problem 4 includes maximization of elastic modulus with two nonlinear inequality constraints for symmetric balanced 12-layered laminated composite. Maximum $E_{x}$ value is obtained as $183.04 \mathrm{GPa}$. In model problem 5, based on EGO method, minimum value for coefficient of thermal expansion $\alpha_{x}$ has been found $-5 \cdot 24 \cdot 10^{-6} /{ }^{\circ} \mathrm{C}$
Figure 4(a) to (e) illustrates the convergence curves of the objective functions for model problems 1-5, respectively, and they help us to analyze the speed of convergence of the algorithm. It can be seen from the figures that although the objective functions and constraints given in problems $1-5$ include trigonometric non-linearities, by only about $10-15$ iterations for the objective function $E_{x}$, and 45 iterations for the objective function $\alpha_{x}$ are enough to reach optimum solutions by using EGO. This is because the EGO process could identify the global optimum with a relatively low evaluation cost. Moreover, the EGO procedure is especially good at modeling the nonlinear, multimodal functions.

Investigation of failure for optimized structures gives some additional information and provides production of safer structures. ${ }^{3}$ Therefore, in order to evaluate the strength performances of optimally designed laminated composites, the failure analysis has been performed and the results are presented in Figures 5 to 8 and Table 4 .

Figure 5 shows variation of tensile failure loads $N_{x}$ with respect to $N_{x} / N_{y}$ for $[ \pm 32.1]_{4 s}$ 16-layered carbon/ epoxy composite. It can be seen from the figure, for all 


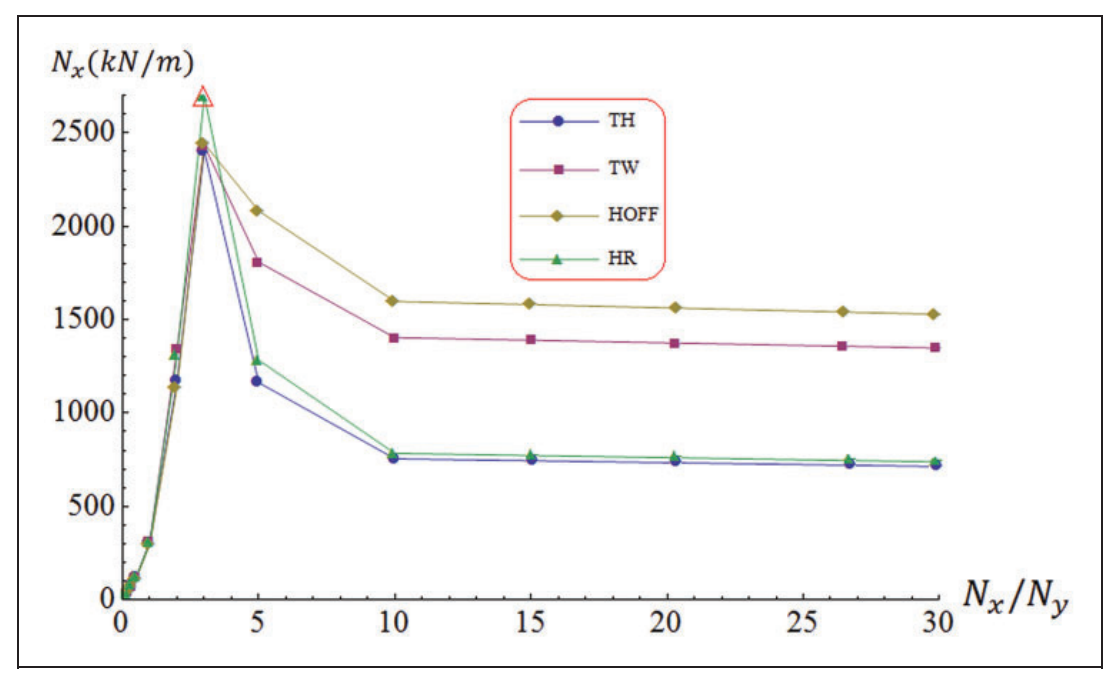

Figure 5. Tensile failure loads for optimized $[ \pm 32.1]_{4 \mathrm{~s}}$ 16-layered carbon/epoxy laminated composite.

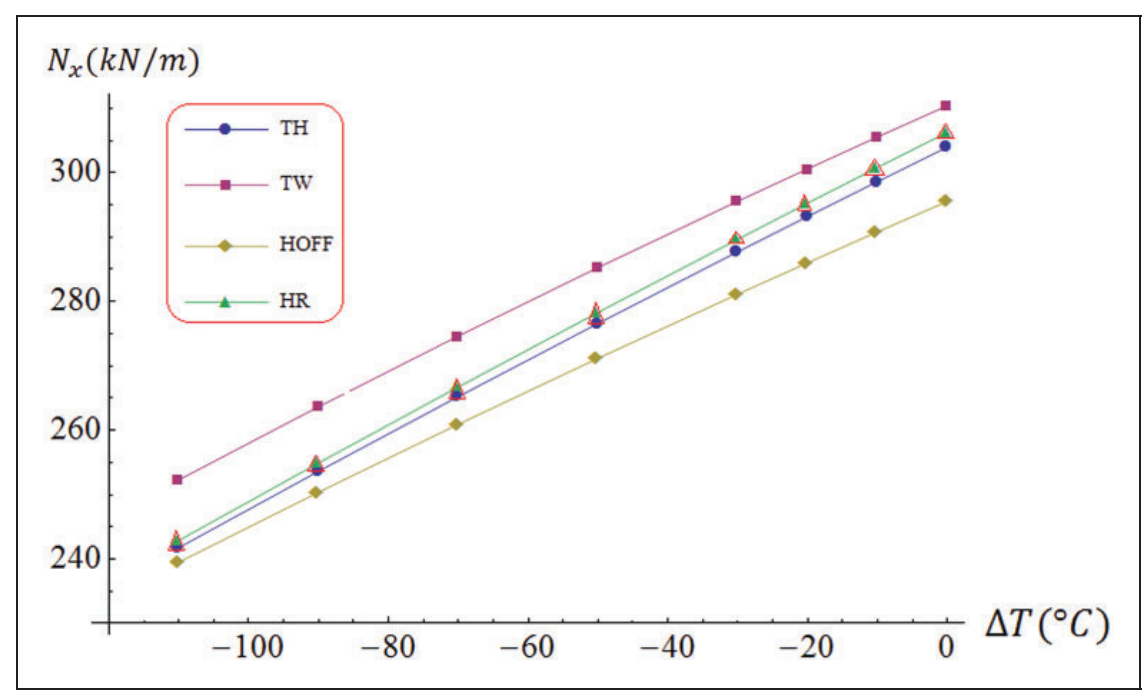

Figure 6. Effect of thermal changes to tensile failure loads for optimized $[ \pm 32.1]_{4 s}$ I6-layered carbon/epoxy laminated composite. (red triangles $(\Delta)$ represent matrix failure).

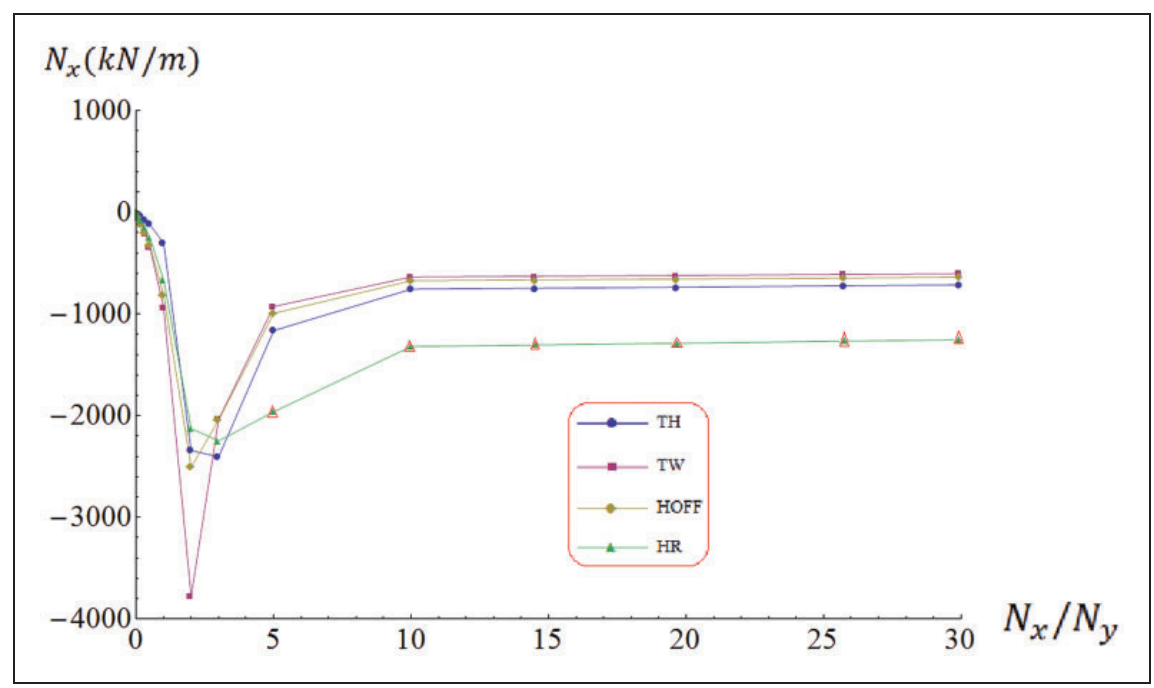

Figure 7. Compression failure loads for optimized $[ \pm 32.1]_{4 \mathrm{~s}}$ 16-layered carbon/epoxy laminated composite. (red triangles $(\Delta)$ represent matrix failure). 


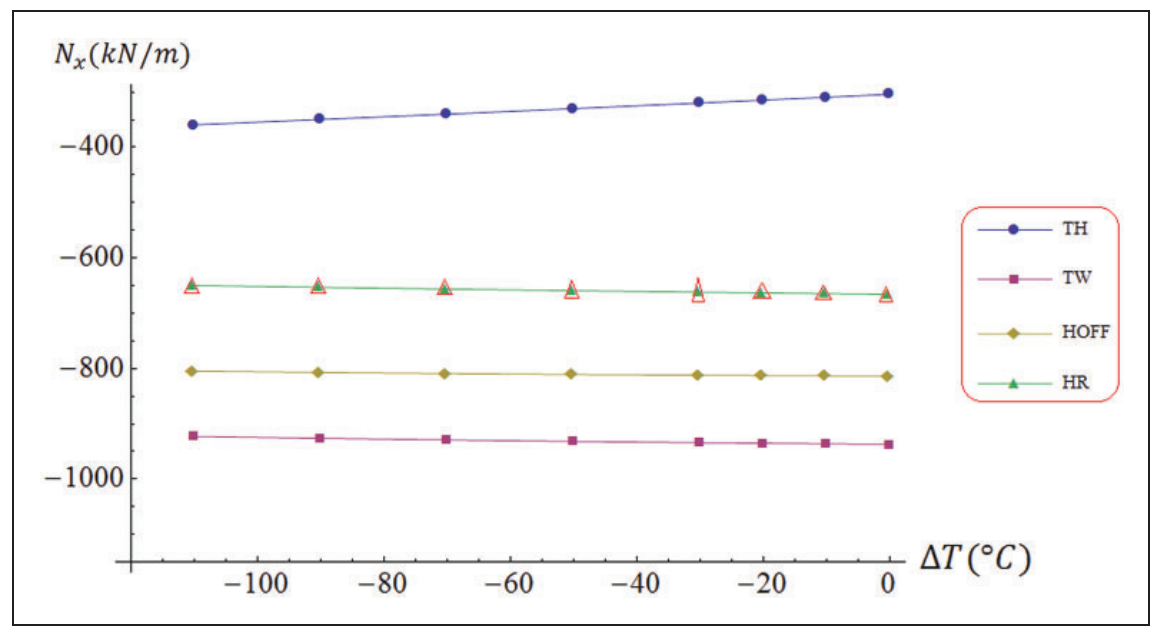

Figure 8. Effect of thermal changes to compression failure loads for optimized $[ \pm 32.1]_{4 s}$ I6-layered carbon/epoxy laminated composite. (red triangles $(\Delta)$ represent matrix failure).

the cases except $N_{x} / N_{y}=3$, matrix failure occurs based on Hashin-Rotem failure criterion. Another observation from the figure is that the first ply failure loads predicted by Tsai-Hill criterion are smaller than the values predicted by the other criteria. Maximum failure load prediction $\left(N_{x}=2698.01 \mathrm{kN} / \mathrm{m}\right)$, calculated from four different failure criteria, is obtained in the case of $N_{x} / N_{y}=3$ by Hashin-Rotem failure criterion. It should be noted that failure behavior of the optimized composite in the interval $[0,10]$ for $N_{x} / N_{y}$ is very critical and it remains stable in the interval $[10,30]$.

In Figure 6, results for effect of thermal changes to tensile failure loads for optimized $\left([ \pm 32.1]_{4 S}\right)$ 16-layered carbon/epoxy composite are given. It can be seen from the figure that (i) matrix failure occurs for all $N_{x} / N_{y}$ values according to Hashin-Rotem failure criterion. It means that thermal changes does not affect fiber or matrix failure types, (ii) tensile failure load $N_{\mathrm{x}}$ rise slightly with increasing thermal change, (iii) the differences in $N_{x}$ with a thermal change of $-110^{\circ} \mathrm{C}$ are $60 \mathrm{kN} / \mathrm{m}$ approximately.

Figure 7 gives compression failure loads for $[ \pm 32.1]_{4 S}$ 16-layered carbon/epoxy composite. It can be observed from the figure that (i) in the interval $[0,5]$ for $N_{x} / N_{y}$, fiber failure occurs; however, matrix failure occurs in the interval $[5,30]$ based on Hashin-Rotem criteria (ii) maximum absolute value of the first ply failure load has been predicted based on Tsai-Wu criterion $\left(N_{x}=-3778.32 \mathrm{kN} / \mathrm{m}\right)$ (iii) similar to Figures 5 and 6 , the failure behaviors in the range [0-10] for $N_{x} / N_{y}$ are very critical for optimized composite and also it is immediately apparent that a significant rise after a sharp fall occurs based on Tsai-Wu criterion.

By comparing the tensile and compression failure load limits of the carbon/epoxy composite (Figures 5 and 7), it can be concluded that absolute value of compression limits higher than tensile limits based on Tsai-Wu, Hoffman, and Hashin-Rotem theories.
Figure 8 shows the effect of thermal changes to compression failure loads for $[ \pm 32.1]_{4 S}$ 16-layered carbon/epoxy composite. It can be seen from the figure that (i) in all the thermal change cases $(\Delta T=$ $-110^{\circ} \mathrm{C},-100^{\circ} \mathrm{C}, \ldots,-10^{\circ} \mathrm{C}, 0^{\circ} \mathrm{C}$ ), matrix failure mechanism become effective based on HashinRotem failure criterion, (ii) the magnitude of failure loads decreases with increasing thermal change based on Tsai-Wu, Hoffman, and Hashin-Rotem criteria. However, an increase is observed in the failure load values calculated based on Tsai-Hill theory, (iii) decreasing ratios with $\Delta T=-110^{\circ} \mathrm{C}$ are $1.5 \%$, $1.1 \%$, and $2.4 \%$ based on Tsai-Wu, Hoffman, and Hashin-Rotem criteria, respectively.

Effect of stacking sequences with thermal changes to failure loads for different 16-layered carbon/epoxy composite can be seen in Table 4.

Five distinct stacking sequences $\left([ \pm 32.1]_{4 S}\right.$ is optimum design, $[90]_{8 S},[0 / 90]_{4 S},[ \pm 45]_{4 S}$, and $[0 / 45]_{4 S}$ are conventional designs) have been considered. Minimum increase occurs in the case of $[90]_{8 S}$, while maximum increase appears for conventional designs $[0 / 90]_{4 S}$ and $[ \pm 45]_{4 S}$ with the thermal change $\left(\Delta T=-110^{\circ} \mathrm{C}\right)$

\section{Experimental verification}

In order to validate the proposed algorithm (EGO), experimental study has been done for E-glass/epoxy laminated composite material. For this purpose, determination of the basic mechanical and thermal properties of E-glass/epoxy has been performed experimentally. After characterization, optimum stacking sequences design for minimization of CTE have been found by EGO as $[ \pm 27]_{S}$. Secondly, the thermal tests have been performed for E-glass/epoxy composites with the optimum stacking sequences $[ \pm 27]_{S}$ in order to compare theoretical and experimental values of CTEs. Besides the conventional ones, $[0]_{8}$ and $[ \pm 45]_{S}$ are also handled in order to verify our design (see Table 5). 
Table 4. Effect of stacking sequences with thermal changes to tensile failure loads for different I6-layered carbon/epoxy laminated composite $\left(N_{x} / N_{y}=1\right)$.

\begin{tabular}{|c|c|c|c|c|}
\hline \multirow{2}{*}{$\begin{array}{l}\text { Stacking sequences } \\
\text { and thermal changes }\end{array}$} & \multicolumn{4}{|c|}{ Tensile failure loads $(\mathrm{kN} / \mathrm{m})$} \\
\hline & Tsai-Hill & Tsai-Wu & Hoffman & Hashin-Rotem \\
\hline $\begin{array}{l}{[ \pm 32.1]_{4 S}} \\
\Delta T=0^{\circ} \mathrm{C}\end{array}$ & $\begin{array}{l}N x=303.990 \\
N y=303.990\end{array}$ & $\begin{array}{l}N x=310.410 \\
N y=310.410\end{array}$ & $\begin{array}{l}N x=295.560 \\
N y=295.560\end{array}$ & $\begin{array}{l}N x(\mathrm{FF})=2194.15 \\
N y(\mathrm{FF})=2194.15 \\
N x(\mathrm{MF})=306.290 \\
N y(\mathrm{MF})=306.290\end{array}$ \\
\hline $\begin{array}{l}{[ \pm 32 . \mathrm{I}]_{4 S}} \\
\Delta T=-110^{\circ} \mathrm{C}\end{array}$ & $\begin{array}{l}N x=241.780 \\
N y=241.780\end{array}$ & $\begin{array}{l}N x=252.300 \\
N y=252.300\end{array}$ & $\begin{array}{l}N x=239.530 \\
N y=239.530\end{array}$ & $\begin{array}{l}N x(\mathrm{FF})=2211.62 \\
N y(\mathrm{FF})=2211.62 \\
N x(\mathrm{MF})=242.890 \\
N y(\mathrm{MF})=242.890\end{array}$ \\
\hline $\begin{array}{l}{[90]_{8 \mathrm{~S}}} \\
\Delta T=0^{\circ} \mathrm{C}\end{array}$ & $\begin{array}{l}N x=120.000 \\
N y=120.000\end{array}$ & $\begin{array}{l}N x=122.332 \\
N y=122.332\end{array}$ & $\begin{array}{l}N x=120.578 \\
N y=120.578\end{array}$ & $\begin{array}{l}N x(\mathrm{FF})=3600.000 \\
N y(\mathrm{FF})=3600.000 \\
N x(\mathrm{MF})=120.000 \\
N y(\mathrm{MF})=120.000\end{array}$ \\
\hline $\begin{array}{l}{[90]_{8 \mathrm{~S}}} \\
\Delta T=-110^{\circ} \mathrm{C}\end{array}$ & $\begin{array}{l}N x=120.000 \\
N y=120.000\end{array}$ & $\begin{array}{l}N x=122.332 \\
N y=122.332\end{array}$ & $\begin{array}{l}N x=120.578 \\
N y=120.578\end{array}$ & $\begin{array}{l}N x(\mathrm{FF})=3600.000 \\
N y(\mathrm{FF})=3600.000 \\
N x(\mathrm{MF})=120.000 \\
N y(\mathrm{MF})=120.000\end{array}$ \\
\hline $\begin{array}{l}{[0 / 90]_{4 S}} \\
\Delta T=0^{\circ} \mathrm{C}\end{array}$ & $\begin{array}{l}N x=1342.73 \\
N y=1342.73\end{array}$ & $\begin{array}{l}N x=1484.30 \\
N y=1484.30\end{array}$ & $\begin{array}{l}N x=1251.54 \\
N y=125 \mid .54\end{array}$ & $\begin{array}{l}N x(\mathrm{FF})=185842 \\
N y(\mathrm{FF})=1858.42 \\
N x(\mathrm{MF})=1908.63 \\
N y(\mathrm{MF})=1908.63\end{array}$ \\
\hline $\begin{array}{l}{[0 / 90]_{4 S}} \\
\Delta T=-110^{\circ} \mathrm{C}\end{array}$ & $\begin{array}{l}N x=982.968 \\
N y=982.968\end{array}$ & $\begin{array}{l}N x=1212.57 \\
N y=1212.57\end{array}$ & $\begin{array}{l}N x=944.786 \\
N y=944.786\end{array}$ & $\begin{array}{l}N x(\mathrm{FF})=1880.07 \\
N y(\mathrm{FF})=1880.07 \\
N x(\mathrm{MF})=1241.62 \\
N y(\mathrm{MF})=1241.62\end{array}$ \\
\hline $\begin{array}{l}{[ \pm 45]_{4 S}} \\
\Delta T=0^{\circ} \mathrm{C}\end{array}$ & $\begin{array}{l}N x=1342.73 \\
N y=1342.73\end{array}$ & $\begin{array}{l}N x=1484.30 \\
N y=1484.30\end{array}$ & $\begin{array}{l}N x=1251.54 \\
N y=125 \mid .54\end{array}$ & $\begin{array}{l}N x(\mathrm{FF})=185842 \\
N y(\mathrm{FF})=1858.42 \\
N x(\mathrm{MF})=1908.63 \\
N y(\mathrm{MF})=1908.63\end{array}$ \\
\hline $\begin{array}{l}{[ \pm 45]_{4 S}} \\
\Delta T=-110^{\circ} \mathrm{C}\end{array}$ & $\begin{array}{l}N x=982.968 \\
N y=982.968\end{array}$ & $\begin{array}{l}N x=1212.57 \\
N y=1212.57\end{array}$ & $\begin{array}{l}N x=944.786 \\
N y=944.786\end{array}$ & $\begin{array}{l}N x(\mathrm{FF})=1880.07 \\
N y(\mathrm{FF})=1880.07 \\
N x(\mathrm{MF})=1241.62 \\
N y(\mathrm{MF})=1241.62\end{array}$ \\
\hline $\begin{array}{l}{[0 / 45]_{4 S}} \\
\Delta T=0^{\circ} \mathrm{C}\end{array}$ & $\begin{array}{l}N x=171.248 \\
N y=171.248\end{array}$ & $\begin{array}{l}N x=174.472 \\
N y=174.472\end{array}$ & $\begin{array}{l}N x=170.082 \\
N y=170.082\end{array}$ & $\begin{array}{l}N x(\mathrm{FF})=2730.90 \\
N y(\mathrm{FF})=2730.90 \\
N x(\mathrm{MF})=171.410 \\
N y(\mathrm{MF})=171.410\end{array}$ \\
\hline $\begin{array}{l}{[0 / 45]_{4 S}} \\
\Delta T=-110^{\circ} \mathrm{C}\end{array}$ & $\begin{array}{l}N x=153.208 \\
N y=153.208\end{array}$ & $\begin{array}{l}N x=157.200 \\
N y=157.200\end{array}$ & $\begin{array}{l}N x=153.358 \\
N y=153.358\end{array}$ & $\begin{array}{l}N x(\mathrm{FF})=2741.70 \\
N y(\mathrm{FF})=2741.70 \\
N x(\mathrm{MF})=153.294 \\
N y(\mathrm{MF})=153.294\end{array}$ \\
\hline
\end{tabular}

Experimental characterization is as follows: E-glass/epoxy laminated composite material is characterized in terms of tensile (ASTM D3039-76) and shear (ASTM D7078/D7078M-05) properties $\left(E_{1}, E_{2}, v_{12}, G_{12}\right)$. Tensile tests have been carried out using Shimadzu AG1 $250 \mathrm{kN}$ testing machine and a computer for data acquisition. To determine tensile properties, at least five specimens per test are used. Longitudinal and transverse properties were determined using unidirectional specimens, $[0]_{6}$ and $[90]_{6}$, respectively. ASTM D 7078/D-7078M-05 standard test method for shear properties of composite materials by V-notched rail shear method was used for characterization of shear modulus $G_{12}$. Thermal properties of the composites have been analyzed by using DMA Q800 dynamic mechanical analyzer. The in-plane thermal expansion coefficients (CTEs) of $[0]_{6},[90]_{6}$ E-glass/epoxy were measured as a function of temperature via dynamic mechanical analysis DMA Q800 instrument. It is used in control force mode with a heating rate of $4^{\circ} \mathrm{C} / \mathrm{min}$. The typical sample dimensions are $15 \mathrm{~mm} \times 4 \mathrm{~mm} \times 1.9 \mathrm{~mm}$. The samples are loaded uniaxially with a tensile stress of $0.1 \mathrm{MPa}$ and the change of the sample dimension with increasing temperature is monitored. The CTE has been determined from the slope of the resultant 
Table 5. Comparison of the theoretical and experimental coefficient of thermal expansions (CTEs) for optimized and conventional stacking sequences.

\begin{tabular}{lcc}
\hline Fiber orientation & $\begin{array}{c}\text { Theoretical } \\
\text { CTE }\left(10^{-6} /{ }^{\circ} \mathrm{C}\right)\end{array}$ & $\begin{array}{l}\text { Experimental } \\
\text { CTE }\left(10^{-6} /{ }^{\circ} \mathrm{C}\right)\end{array}$ \\
\hline$[27 /-27 /-27 / 27]$ & 8.61 & 9.64 \\
{$[0 / 0 / 0 / 0]$} & 10.02 & 12.57 \\
{$[45 /-45 /-45 / 45]$} & 16.83 & 14.15 \\
\hline
\end{tabular}

Table 6. Elastic moduli, Poisson's ratio, shear modulus, fiber volume fraction, coefficient of thermal expansions values of the E-glass/epoxy composite.

\begin{tabular}{lllllll}
\hline $\begin{array}{l}E_{1} \\
(\mathrm{GPa})\end{array}$ & $\begin{array}{l}E_{2} \\
(\mathrm{GPa})\end{array}$ & $v_{12}$ & $\begin{array}{l}G_{12} \\
(\mathrm{GPa})\end{array}$ & $v_{f}$ & $\begin{array}{l}\alpha_{1} \\
\left(10^{-6} /{ }^{\circ} \mathrm{C}\right)\end{array}$ & $\begin{array}{l}\alpha_{2} \\
\left(10^{-6} /{ }^{\circ} \mathrm{C}\right)\end{array}$ \\
\hline 22.2 & 11.5 & 0.33 & 2 & 0.41 & 10.02 & 28.41 \\
\hline
\end{tabular}

expansion temperature plots. CTEs of the E-glass/ epoxy for fiber and transverse directions are obtained as $\alpha_{1}=10.02 .10^{-6} /{ }^{\circ} \mathrm{C}$ and $\alpha_{2}=28.41 .10^{-6} /{ }^{\circ} \mathrm{C}$ based on the formulation as

$$
\alpha=\frac{\Delta L}{L \times \Delta T}
$$

Experimentally determined thermo-mechanical properties of unidirectional E-glass/epoxy laminated composite under static loading are given in Table 6 . Regarding Table 5, it is observed that the theoretical results are in good agreement with the experimental ones. Another observation is that when the CTE values for $[ \pm 27]_{S}$ compared with conventional designs, the minimum value as expected is reached by the optimum design.

\section{Conclusion}

In the current study, EGO method has been proposed to design the dimensionally stable laminated carbon/ epoxy composites subjected to mechanical and hygrothermal loadings. First, the results of optimum stacking sequences designs using EGO were compared with those using the GA, SA, and GPSA algorithms. Secondly, verification of EGO results has been achieved experimentally for E-glass/ epoxy composite. Afterwards, comparison of failure loads of the optimized carbon/epoxy composites by using Tsai-Hill, Tsai-Wu, Hoffman, and Hashin-Rotem failure criteria including thermal and moisture effects has been performed.

Based on the studies carried out, we have concluded with the following observations:

1. It was observed that the proposed algorithm EGO has potential to optimize dimensionally stable composites.
2. EGO method produces solutions better than or as good as widely used stochastic search algorithms GA, SA, and GPSA.

3. The studies including experimental verification of the optimization algorithms are quite few in the literature. In this study, comparison of numerical and experimental results is examined and good agreement is observed.

4. In the literature, it is mainly focused on either failure analysis of laminated composites with conventional stacking sequences (i.e., $[0 / 90]_{4 S}$ and $\left.[ \pm 45]_{4 S}\right)$ or designing composites resistant to fracture using failure criteria as optimization constraints. However, in the present paper, the failure analysis is considered to evaluate the strength performances of optimally designed laminated composites (i.e., $[ \pm 32.1]_{4 S}$ ). By this approach, failure loads of the optimum laminated composites are additionally determined. In conclusion, the present study fills a gap in this respect.

\section{Declaration of conflicting interests}

The author(s) declared no potential conflicts of interest with respect to the research, authorship, and/or publication of this article.

\section{Funding}

The author(s) disclosed receipt of the following financial support for the research, authorship, and/or publication of this article: This work was supported by Scientific Research Project Division of Izmir Katip Çelebi University (grant number 2013-2-FMBP-51).

\section{References}

1. Kollar LP and Springer GS. Mechanics of composite structures. Cambridge, UK: Cambridge University Press, 2003.

2. Le Rich R and Gaudin J. Design of dimensionally stable composites by evolutionary optimization. Compos Struct 1998; 41: 97-111.

3. Aydin L and Artem HS. Comparison of stochastic search optimization algorithms for the laminated composites under mechanical and hygrothermal loadings. J Reinf Plast Compos 2011; 30: 1197-1212.

4. Bressan F, De Bona F and Soma A. Design of composite laminates with low thermal expansion. Proc IMechE, Part L: J Materials: Design and Applications 2004; 218: 201-209.

5. Rangarajan A, D'Mello RJ, Sundararaghavan V, et al. Minimization of thermal expansion of symmetric, balanced, angle ply laminates by optimization of fiber path configurations. Compos Sci Technol 2011; 71: 1105-1109.

6. Zhang Z, Zhong W and Song H. Design of hybrid composites with zero coefficient of thermal expansion. J Mater Sci Technol 1996; 12: 241-248.

7. Aydin L, Uğural BK and Özdoğan E. Design of dimensionally stable flax/ polypropylene composite plates by using stochastic optimization. In: 4th International polymeric composites symposium, exhibition and brokerage event, İzmir, May 2015. 
8. Marín L, Trias D, Badalló P, et al. Optimization of composite stiffened panels under mechanical and hygrothermal loads using neural networks and genetic algorithms. Compos Struct 2012; 94: 3321-3326.

9. Khalil M, Bakhiet E and El-Zoghby A. Optimum design of laminated composites subjected to hygrothermal residual stresses. Proc IMechE, Part L: J Materials: Design and Applications 2001; 215: 175-186.

10. Ananda Rao M, Ratnam C, Srinivas J, et al. Optimum design of multilayer composite plates using simulated annealing. Proc IMechE, Part L: J Materials: Design and Applications 2002; 216: 193-197.

11. Jones DR, Schonlau M and Welch WJ. Efficient global optimization of expensive black-box functions. J Global Optim 1998; 13: 455-492.

12. Todoroki A and Sekishiro M. Modified efficient global optimization for a hat-stiffened composite panel with buckling constraint. AIAA J 2008; 46: 2257-2264.

13. Glaz B, Friedmann PP and Liu L. Efficient global optimization of helicopter rotor blades for vibration reduction in forward flight. In: 11th AIAA/ISSMO multidisciplinary analysis and optimization conference, portsmouth, Virginia, 6-8 September 2006.

14. Aydin L. Design of dimensionally-stable laminated composites subjected to hygro-thermo-mechanical loading by stochastic optimization methods. PhD Thesis, Izmir Institute of Technology, Urla, İzmir, Turkey, 2011.

15. Kaw AK. Mechanics of composite materials. 2nd ed. Boca Raton: CRC Press Taylor \& Francis Group, 2006.

16. Daniel IM. Failure of composite materials. Strain 2007; 43: 4-12.

17. Tsai SW. Strength theories of filamentary structures. In: RT Schwartz and HSS Schwartz (eds)
Fundamental aspects of fiber reinforced plastic composites. New York: Wiley Interscience, 1968.

18. Wu EM. Strength and fracture of composites. In: LJ Broutman (ed.) Composite materials. vol. 5, New York: Academic Press, 1974.

19. Daniel IM and Ishai O. Engineering mechanics of composite materials. New York: Oxford University Press, 1994

20. Hoffman O. The brittle stregth of orthotropic materials. J Compos Mater 1967; 1: 200-297.

21. Hashin $\mathrm{Z}$ and Rotem A. A fatigue failure criterion for fibre reinforced materials. J Compos Mater 1973; 7: 448-464.

22. Gurdal Z, Haftka RT and Hajela P. Design and optimization of laminated composite materials. New York: John Wiley\&Sons, Inc, 1999.

23. Sacks J, Welch WJ, Mitchell TJ, et al. Design and analysis of computer experiments (with discussion). Stat $S c i$ 1996; 4: 409-435.

24. Schonlau M. Computer experiments and global optimization. PhD Thesis, University of Waterloo, Waterloo, Ontario, 1997.

25. Aydin L and Artem HS. Multi-objective genetic algorithm optimization of the composite laminates as a satellite structure material for coefficient of thermal expansion and elastic modulus. In: S Kurnaz, F Ince and S Basturk (eds) 4th international conference on recent advances in space technologies, RAST '09, Istanbul, Turkey, June 2009, pp.114-119. IEEE. 